\title{
Tomato Cultivation in a Plant Factory with Artificial Light: Effect of UV-A Irradiation During the Growing Period on Yield and Quality of Ripening Fruit
}

\author{
Takayuki Kobayashi*,** and Toshihito Tabuchi
}

Department of Advanced Food Sciences, College of Agriculture, Tamagawa University, Machida 194-8610, Japan

\begin{abstract}
Dwarf cherry tomatoes 'Red Robin' and 'Tiny Tim Red' were cultivated in two sections. The two sections were set as (1) section irradiated only by fluorescent lamps (main wavelengths 433, 543, and $610 \mathrm{~nm}$; $230 \mu \mathrm{mol} \cdot \mathrm{m}^{-2} \cdot \mathrm{s}^{-1}$ of photosynthetic photon flux density) and non-treated with UV-A irradiation (hereafter, non-UVA), and (2) section irradiated with fluorescent lamps and treated with UV-A irradiation (maximum peak emission: $352 \mathrm{~nm} ; 15.1 \mathrm{~W} \cdot \mathrm{m}^{-2}$ ultraviolet radiation intensity; hereafter, $\mathrm{t}-\mathrm{UVA}$ ). The fruit weight per plant and the number of fruits per plant were not significantly affected by cultivar or section. Regarding fruit quality, the fruit cracking rate was lower in the t-UVA than in non-UVA section. There were no anatomical or histochemical differences in fruit structure or distribution of pigments such as lycopene or $\beta$-carotene, but the shape of the pigment in the epidermal cells was needle-shaped in the non-UVA and unclearly-shaped in the t-UVA, so the pigment shape was different between the two sections. In addition, the number of layers of the hypodermis in the exocarp that accumulated the pigment was smaller in the t-UVA than in non-UVA section. Fruit components in t-UVA showed increased total soluble solids (TSS), titratable acidity (TA), and ascorbic acid content, but a decreased carotenoid content. Therefore, it was shown that UV-A irradiation had a positive effect on the TSS, TA and ascorbic acid content and had a negative effect on the size of the fruit per fruit and the carotenoid content. UV irradiation did not affect the yield per plant. Comparing 'Red Robin' and 'Tiny Tim Red', there was no significant difference in yield, but the fruit size of 'Red Robin' was larger, while and the fruit component of 'Tiny Tim Red' was higher than that of 'Red Robin'. In conclusion, when cultivating tomato plants in a plant factory, further improvements in fruit size and composition are expected by appropriately adjusting the time and intensity of UV irradiation for each cultivar.
\end{abstract}

Key Words: anatomical fruit structure, ascorbic acid, titratable acidity, total soluble solids.

\section{Introduction}

A plant factory with artificial light has an environmental parameter control mechanism to adjust light, carbon dioxide, air temperature, and humidity, the nutrition solution and water, and a multi-layered hydroponic cultivation shelf (Kozai, 2013a; Benke and Tomkins, 2017). Plants can be cultivated regardless of the weather by isolating the cultivation shelves from the outside environment. Therefore, leafy vegetables or herbs with a short plant height that can be cultivated on multi-

Received; January 3, 2021. Accepted; September 21, 2021.

First Published Online in J-STAGE on November 30, 2021.

Special Issue "Plant factory and modern greenhouse".

No conflicts of interest declared.

* Corresponding author (E-mail: takayuki-koba05@fol.hi-ho.ne.jp).

** Present address: Smart Agriculture Research Division, Tokyo

Metropolitan Agriculture and Forestry Research Center,

Tachikawa 190-0013, Japan. layered cultivation shelves are produced in plant factories and are mainly sold in fresh markets. On the other hand, few fruit vegetables are cultivated in plant factories, and strawberry fruits are produced in some plant factories (Shamshiri et al., 2018). Therefore, the cultivation of fruit vegetables in plant factories could contribute to the diversification of cultivated production. In one study on tomatoes in a plant factory with artificial light, the plant factory was used to produce tomato seedlings. Results for light quality and water efficiency, $\mathrm{CO}_{2}$ and light energy use to produce higher quality tomato seedlings to improve productivity in greenhouses have been reported (Kozai, 2013b). Kato et al. $(2010,2011)$ bred a line that crossed a transgenic tomato line that expresses the miraculin gene driven by the CaMV 35S promoter and a dwarf cultivated tomato, while the plant productivity of recombinant proteins in a plant factory have also been reported. Ohashi-Kaneko et al. (2017) conducted research using wild tomato 
species and dwarf mutant lines, and reported that lines with increased content of soluble solids and vitamin C in the fruit during a 24-hour photoperiod under low photosynthetic photon flux density (PPFD, $180 \mu \mathrm{mol} \cdot \mathrm{m}^{-2} \cdot \mathrm{s}^{-1}$ ) are useful germplasm resources. However, few studies have investigated tomato cultivars suitable for use in plant factories with artificial light.

In a plant factory where light quality can be adjusted, it is possible to use ultraviolet (hereinafter, UV) irradiation when cultivating vegetables. It has been reported that UV irradiation increased the phytochemical contents such as flavonoids, carotenoids, antioxidants and phenolic compounds in vegetables (Lee et al., 2014; He et al., 2020). In tomatoes, there are many studies showing that irradiation with UV radiation of fruits postharvest increases antioxidants, phenolic compounds, flavonoids, carotenoids, and soluble solids content (Castagna et al., 2013, 2014; Kasim and Kasim, 2015; Mariz-Ponte et al., 2019). Therefore, beneficial effects of irradiating tomato fruits with ultraviolet radiation are expected, and it is possible to obtain fruits of better quality, but there are few studies using UV irradiation in plant factories. In this study, we investigated (1) cultivation using dwarf cultivars and (2) the effect on tomato fruit quality under UV-A irradiation conditions in a plant factory.

\section{Materials and Methods}

\section{Plant materials}

The dwarf cherry tomato cultivars (Solanum lycopersicum) 'Red Robin' and 'Tiny Tim Red' were used in this study (Fig. 1). These cultivars were selected because of their varietal characteristics as shown below. 'Red Robin' has a growth habit determinate, dwarf plant size $(23-30 \mathrm{~cm}$ tall) and all fruits ripen at the time. 'Tiny Tim Red' has a growth habit determinate, is selfpruning $(s p)$ and is a dwarf $(d)$ plant $(15-30 \mathrm{~cm}$ tall).

Seeds of these cultivars were sown on urethane mats $(23 \mathrm{~mm} \times 23 \mathrm{~mm} \times 27 \mathrm{~mm} ; \quad$ width $\times$ length $\times$ height $)$

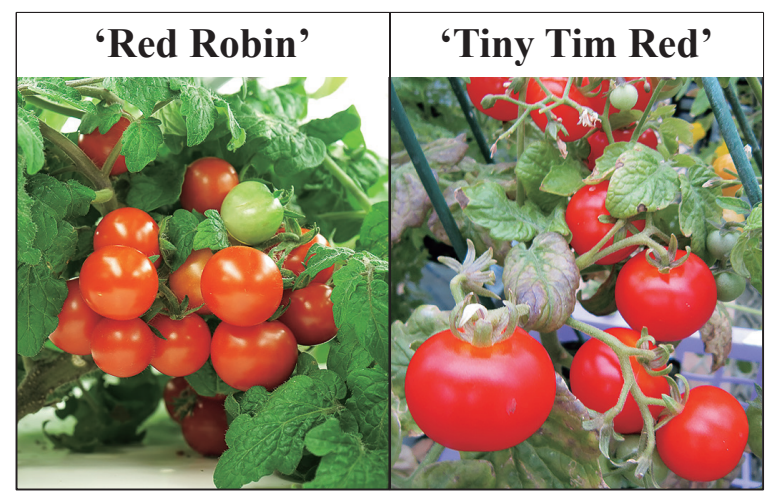

Fig. 1. Plants of cultivated cherry tomatoes used in this study (left side: 'Red Robin', right side: 'Tiny Tim Red'). When the fruits of these cultivars were fully ripened, they turned red. soaked in water and allowed to stand in a dark place at $25^{\circ} \mathrm{C}$ for 24 hours. On the 10th day after sowing, the germinated seedlings with true leaves were transplanted into a container $(376 \mathrm{~mm} \times 602 \mathrm{~mm} \times 76 \mathrm{~mm})$, and the container was placed under a white fluorescent lamp (hereinafter, FL) with main wavelengths of 433, 543, and $610 \mathrm{~nm}$ (FHF32EX-N-H; TOSHIBA LIGHTING \& TECHNOLOGY Corp., Kanagawa, Japan; Supplemental Fig. S1) for 30 days. The environment for raising seedlings was a $16 \mathrm{~h} / 8 \mathrm{~h}$ photoperiod (light/dark), $120 \mu \mathrm{mol} \cdot \mathrm{m}^{-2} \cdot \mathrm{s}^{-1}$ of PPFD, $25 \pm 3^{\circ} \mathrm{C}$ air temperature, $65 \pm 5 \%$ relative humidity, and $\mathrm{CO}_{2}$ concentration was adjusted so that it was maintained at $1,000 \mathrm{ppm}$. As the culture solution, OAT-house A solution (OAT Agrio Co., Ltd., Tokyo, Japan), maintained at electrical conductivity (EC) of $1.2 \mathrm{dS} \cdot \mathrm{m}^{-1}$ and $\mathrm{pH} 6.5$ was used as a nutrient solution. On the thirtieth day after germination, four seedlings were transplanted into a container $(423 \mathrm{~mm} \times 684 \mathrm{~mm} \times 100 \mathrm{~mm})$ which was a noncirculating type deep-flow technique hydroponic apparatus (DFT) and cultivated in a section on a multilayered cultivation shelf under the following environmental conditions (Fig. 2).

Each section was set with a shelf was divided into two parts based on the type of light quality. The two sections were set as (1) section irradiated only fluorescent lamps and non-treated with UV-A irradiation, and (2) section irradiated with fluorescent lamps and treated with UV-A irradiation. The two cultivation sections are indicated by (1) section: non-UVA and (2) section: t-UVA in this study. The cultivation conditions were maintained with a white fluorescent lamp $\left(230 \mu \mathrm{mol} \cdot \mathrm{m}^{-2} \cdot \mathrm{s}^{-1}\right.$ of PPFD), a fluorescent blacklight lamp with a maximum peak emission at $352 \mathrm{~nm}$ $\left(15.1 \mathrm{~W} \cdot \mathrm{m}^{-2}\right.$ UV radiation intensity; FHF32BLB-T; TOSHIBA LIGHTING \& TECHNOLOGY; Supplemental Fig. S2) used in UV-A irradiation, and a photoperiod of $8 \mathrm{~h} / 16 \mathrm{~h}$ (light/dark) on the top side of the plant. Air temperature, relative humidity and $\mathrm{CO}_{2}$ concentration were adjusted to maintain levels of $25 \pm 2{ }^{\circ} \mathrm{C}$, $60 \pm 10 \%$ and $1,000 \mathrm{ppm}$, respectively. A culture solution was used in OAT-house A solution (maintained in EC: $1.2 \mathrm{dS} \cdot \mathrm{m}^{-1}$ and $\mathrm{pH} 6.5$ ). The culture solution was changed once a week. Pollination was accomplished by flicking all flowers at the flowering stage. Three months after transplanting, ripe fruits were harvested. For the fruits, the yield per plant and the rate of cracking fruits out of the total number of harvested fruits were calculated. For the size of the fruit, the fruit diameter and fruit weight were measured with electronic digital calipers $(\mathrm{mm})$ and a digital scale $(\mathrm{g})$, respectively. Then, the fruits were used for anatomical and histochemical investigations of the exocarp and fruit composition analysis.

\section{Anatomical and histochemical investigation of fruits}

The external appearance of the fruit structure was 

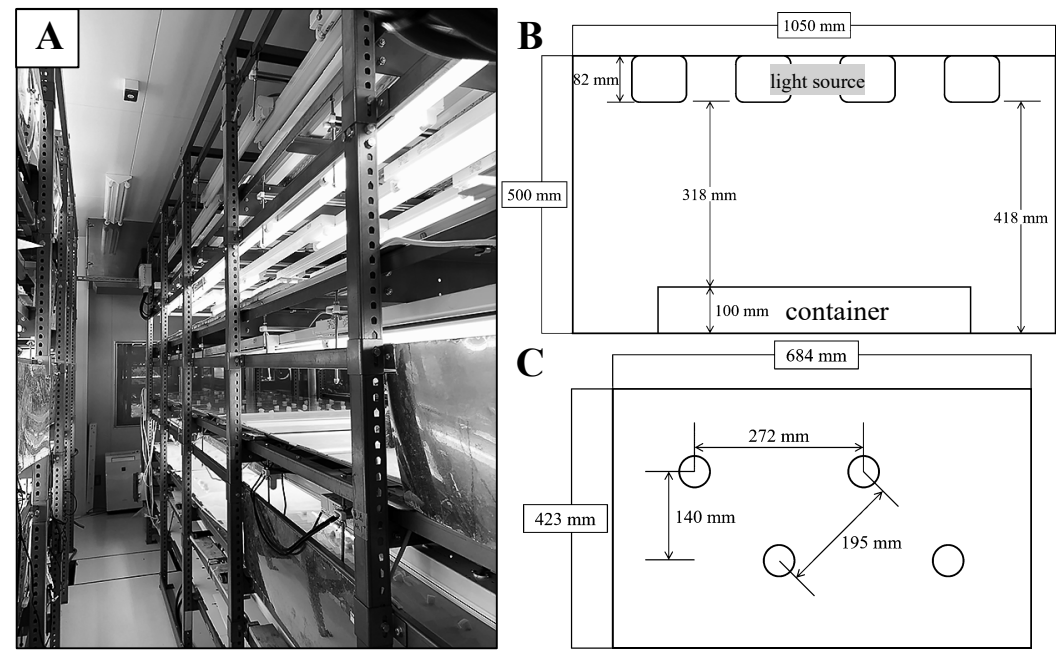

Fig. 2. Multi-layer cultivation shelves (A) installed in the cultivation room $(8274 \mathrm{~mm} \times 13636 \mathrm{~mm} \times 3000 \mathrm{~mm})$. A container with transplanted seedlings was placed in one cultivation layer $(1050 \mathrm{~mm} \times 5010 \mathrm{~mm} \times 500 \mathrm{~mm})$, and a cultivating space in one cultivation layer (B) and planting distance in a container $(\mathrm{C})$.

investigated by observing tissue pieces prepared by peeling the pericarp of ripe red-colored fruit. In addition, $30 \mu \mathrm{m}$ fresh cross-sections were cut by an automatic plant microtome (MT-3; Nippon Medical \& Chemical Instruments Co., Ltd., Osaka, Japan). Then, each cross-section was used for histochemical detection of cuticle substances in the exocarp. Fresh sections were washed with $50 \%$ ethanol for three minutes and then immersed in $0.02 \%$ Sudan IV $70 \%$ ethanol for 20 minutes. Then, they were washed with $50 \%$ ethanol for one minute (Jensen, 1962). For anatomical and histochemical investigation, a light microscope (Olympus BX51; Olympus Corp., Tokyo, Japan) was used for observations.

\section{Analysis of fruit components}

All ripe fruits harvested from four plants from each of the two sections were randomly sorted so that the number of fruits was divided into five groups for replication. The number of fruits per group in the non-UVA and t-UVA section for each cultivar was as follows: 15 16 fruits and 16 fruits of 'Red Robin', 19-20 fruits and nine fruits of 'Tiny Tim Red'. A paste was made from each ripe fruit, and the required volume was weighed from the paste for to measure the ascorbic acid and carotenoid content. Next, a juice extract was made with the remaining paste. Total soluble solids (TSS) in $1 \mathrm{~mL}$ of juice extract were measured using a digital refractometer (PAL-1; ATAGO Co., Ltd., Tokyo, Japan) and expressed as Brix (\%). Titratable acidity (TA) in $25 \mathrm{~mL}$ juice extract filled up to $50 \mathrm{~mL}$ with distilled water was determined by titrating with $0.1 \mathrm{~N} \mathrm{NaOH}$, and the result was expressed in terms of citric acid. The TSS to TA ratio was also calculated. The content of ascorbic acid in the $1.0 \mathrm{~g}$ paste was measured by using a Reflectoquant Ascorbic Acid Test with a reflectometer
(RQ flex plus 10; Merck Corp., Darmstadt, Germany). The carotenoid content in the $1.0 \mathrm{~g}$ paste was measured by using a spectrophotometer (UV-1200; Shimadzu Corp., Kyoto, Japan) with a measurement method based on Nagata and Yamashita (1992). Component analysis was repeated 5 times (derived from the 5 divisions of the number of ripe fruits), and the results are shown as the mean \pm standard error.

\section{Statistical analysis}

Statistical analysis was performed using EZR software (EZR software version 1.5.3; Kanda, 2013). Data were analyzed by two-way analysis of variance (ANOVA). When the interaction of two-way ANOVA was significant, the data were analyzed by Tukey's test.

\section{Results and Discussion}

Effects of ultraviolet radiation on fruit yield and fruit size

The fruit weight per plant showed no significant difference in terms of cultivar or section by two-way ANOVA, and there was no effect for the interaction between cultivar and section $(\mathrm{C} \times \mathrm{S})$ (Table 1). This result was also observed for the difference in the number of fruits per plant. The fruit weight per fruit was significantly heavier for 'Red Robin' than 'Tiny Tim Red' at $P<0.001$ and a significant difference in the effect of UV-A irradiation treatment was observed at $P<0.01$, but no significant difference was found in the interaction (Table 1). The fruit diameter per fruit was significantly different between cultivars at $P<0.001$ and the fruit diameter per fruit of 'Red Robin' was larger than that of 'Tiny Tim Red', but there was no significance in the sections or the $(\mathrm{C} \times \mathrm{S})$ (Table 1).

Bacci et al. (1999) showed that tomato plants UV-B radiated by using Q-PANEL UV-B 313 FL (maximum 
Table 1. Effects of ultraviolet radiation on yield and fruit size of 'Red Robin' and 'Tiny Tim Red'.

\begin{tabular}{|c|c|c|c|c|c|c|c|c|}
\hline Cultivar & Section & $\begin{array}{l}\text { Fruit weight } \\
\text { (g/plant) }\end{array}$ & $\begin{array}{l}\text { Number of fruits } \\
\text { (fruits/plant) }\end{array}$ & $\begin{array}{l}\text { Fruit weight } \\
\text { (g/fruit) }\end{array}$ & $\begin{array}{l}\text { Fruit diameter } \\
\quad(\mathrm{mm} / \text { fruit })\end{array}$ & $\begin{array}{c}\text { Total number of } \\
\text { harvested fruits } \\
\text { (fruits) }\end{array}$ & $\begin{array}{l}\text { Number of } \\
\text { cracked fruits } \\
\text { (fruits/plant) }\end{array}$ & $\begin{array}{c}\text { Cracked fruits } \\
(\% / \text { plant })\end{array}$ \\
\hline \multirow{2}{*}{ 'Red Robin' } & non-UVA & $150.5 \pm 31.6^{y}$ & $19.8 \pm 2.8$ & $7.6 \pm 0.3$ & $22.5 \pm 0.3$ & 79 & $12.5 \pm 1.7$ & $63.5 \pm 1.1$ \\
\hline & t-UVA & $131.8 \pm 20.3$ & $20.0 \pm 1.6$ & $6.6 \pm 0.3$ & $21.7 \pm 0.3$ & 80 & $13.0 \pm 2.6$ & $63.2 \pm 8.4$ \\
\hline \multirow{2}{*}{ 'Tiny Tim Red' } & non-UVA & $148.4 \pm 29.8$ & $24.0 \pm 4.9$ & $6.2 \pm 0.2$ & $20.4 \pm 0.3$ & 96 & $16.8 \pm 3.4$ & $69.8 \pm 0.3$ \\
\hline & t-UVA & $65.1 \pm 22.0$ & $11.3 \pm 3.8$ & $5.8 \pm 0.3$ & $20.3 \pm 0.4$ & 45 & $8.5 \pm 2.9$ & $74.9 \pm 1.2$ \\
\hline \multirow{3}{*}{ Significance $^{z}$} & Cultivar (C) & NS & NS & $* * *$ & $* * *$ & - & NS & NS \\
\hline & Section (S) & NS & NS & $* *$ & NS & - & NS & NS \\
\hline & $(\mathrm{C}) \times(\mathrm{S})$ & NS & NS & NS & NS & - & NS & NS \\
\hline
\end{tabular}

z NS indicate not significant; asterisks are significant differences at *** $P<0.001, * * P<0.01, * P<0.05$ by two-way ANOVA (fruit weight and number of fruits: $\mathrm{n}=4$, fruit weight and diameter: $\mathrm{n}=79,80,96,45)$. "—" Two-way ANOVA was not used.

y The data are mean \pm standard error.

peak emission: $315 \mathrm{~nm}$; UV radiation intensity: $0.11 \mathrm{~W} \cdot \mathrm{m}^{-2}$ ) for seven hours per day resulted in reduction in fruit weight per plant and a similar or greater number of fruits per plant. Mariz-Ponte et al. (2019) reported that UV-A for $1 \mathrm{~h}$ per day using fluorescent blacklight ( $368 \mathrm{~nm} ; 0.8 \mathrm{~W} \cdot \mathrm{m}^{-2}$ ) and UV-B for 2 min per day using $8 \mathrm{~W}$ lamps TFP-M/WL $\left(312 \mathrm{~nm} ; 2.94 \mathrm{~W} \cdot \mathrm{m}^{-2}\right)$ for irradiation significantly increased the number of fruits per plant. In our study, the fruit weight per plant and number of fruits per plant were not affected by cultivar or section because there was no significant difference in the measured values of the fruit weight or the number of fruits, which was inconsistent with Bacci et al. (1999) and Mariz-Ponte et al. (2019). On the other hand, UV-A irradiation was accompanied by a decrease in fruit weight and fruit diameter per fruit (Table 1). These results were the same as Bacci et al. (1999) and Mariz-Ponte et al. (2019). Mariz-Ponte et al. (2019) pointed out that a decrease in fruit size may be accompanied by an increase in the number of fruits. However, in our results, the number of fruits of 'Red Robin' and 'Tiny Tim Red' did not increase significantly. Therefore, UV irradiation of tomato plants affected the size of fruits, especially the fruit weight per fruit.

\section{External appearance of the fruit, and exocarp pigment distribution}

Fruit cracking was observed in the harvested ripe fruits (Fig. 3). The number of cracked fruits to harvested fruits showed no significant difference in cultivars or sections by two-way ANOVA (Table 1). There was no effect for the interaction between cultivar and section $(\mathrm{C} \times \mathrm{S})$. This result was also observed for the rate of cracked fruits. Fruit cracking occurred in all cultivation areas. When the pericarp was observed from the outside, a yellowish epidermis was observed in both cultivars, and a needle-shaped red pigment like lycopene was accumulated in the epidermal cells (Fig. 4). The pigment had a needle-shape in the non-UVA section, but was an unclear shape in t-UVA, and a difference in
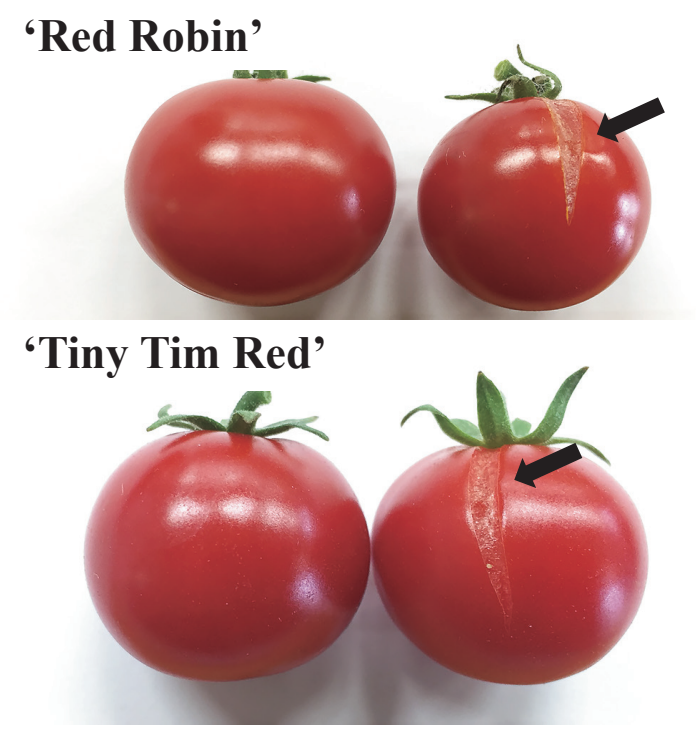

Fig. 3. Fruit cracking symptoms were observed in the harvested ripe fruits (left: normal fruit, right: cracked fruit). Clear crevices were found on the surface of some fruits (black arrows).

the pigment shape was observed (Fig. 4: black arrow). In particular, the epidermal cells of t-UVA in 'Tiny Tim Red' were prominently observed and contained an unclear shaped red pigment.

Regarding fresh cross-sections (Fig. 5), the exocarp was composed of a one layer epidermis and 3 to 4 layers of hypodermis, and the mesocarp consisting of thinwalled parenchymatous cells was observed just below the hypodermis. The pericarp constituent cells contained a red-colored pigment. Although there was no difference in the pericarp structure in the cultivation area, the number of hypodermis layers in which pigment distribution was observed was 1 to 2 layers in t-UVA and 3 to 4 layers in non-UVA, and there were fewer layers in t-UVA than non-UVA. The epidermis of the exocarp was most strongly stained with Sudan IV in both cultivars, and it was found that the cuticle sub- 


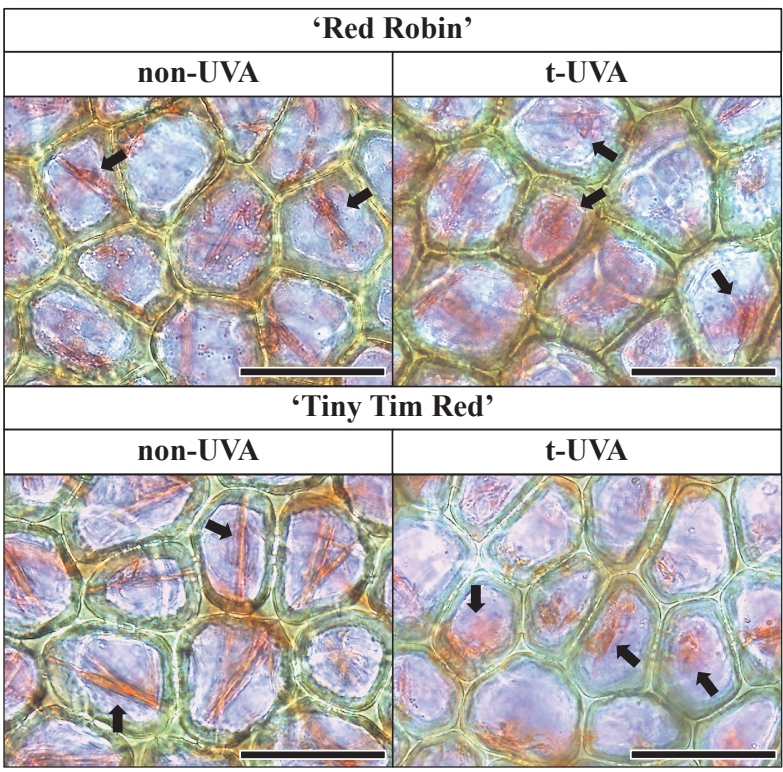

Fig. 4. Epidermal structure and pigment distribution of the pericarp in 'Red Robin' and 'Tiny Tim Red'. Indicates left: non-UVA, right: t-UVA. Black arrows indicate pigment in the epidermal cells. Different pigment shapes were observed between nonUVA (needle-shape) and t-UVA (unclear shape). The black scale bar is $50 \mu \mathrm{m}$.

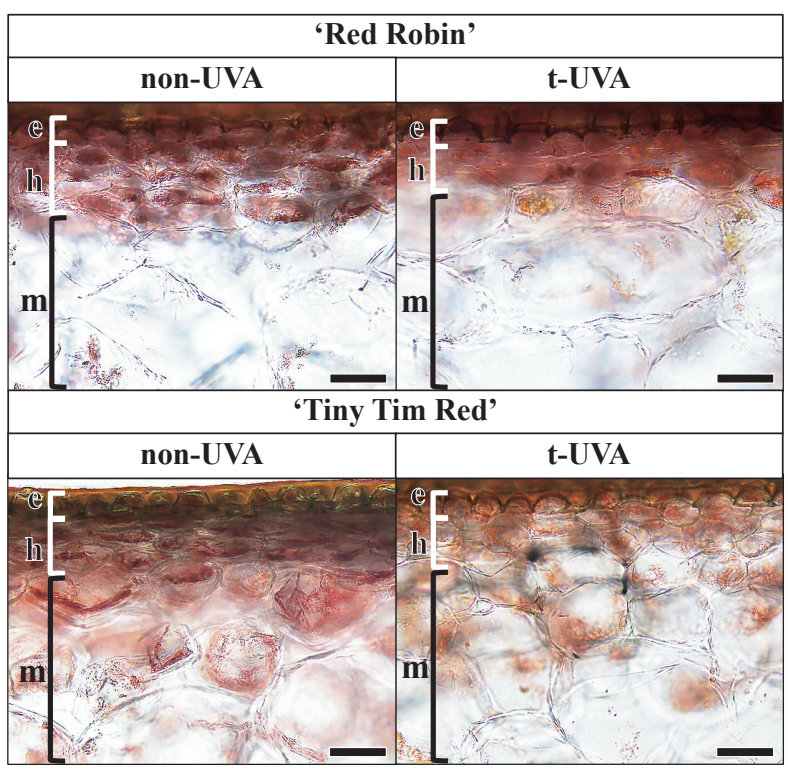

Fig. 5. Exocarp structure and pigment distribution in fresh crosssections of 'Red Robin' and 'Tiny Tim Red'. Indicates left: non-UVA, right: t-UVA. Symbols in the figure indicate e: epidermis, h: hypodermis and m: mesocarp. The black scale bar is $50 \mu \mathrm{m}$.

stance was localized (Fig. 6). In addition, no difference was observed in the localization of the cuticle substance in two sections. According to Peet (1992), tomato fruit cracking occurs when fruit ripens or other factors reduce the strength and elasticity of the pericarp, while there is a rapid net influx of water and solute into the fruit. In another report, it was shown that when exces-

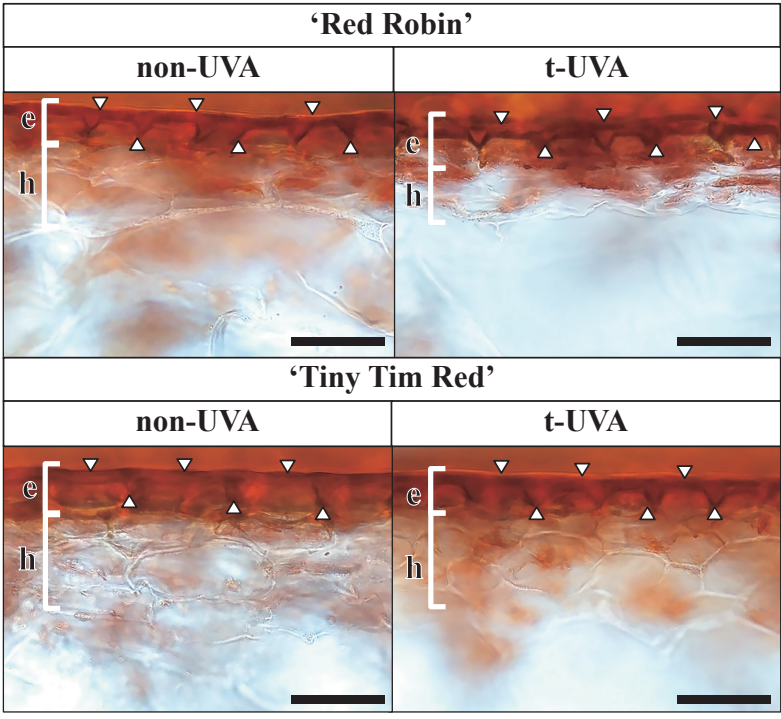

Fig. 6. Detection of cuticle substances in the exocarp. The cuticle substances were stained orange by Sudan IV. Indicates left: non-UVA, right: t-UVA. Symbols in the figure indicate e: epidermis, h: hypodermis and white arrow: cuticle layer. The black scale bar is $50 \mu \mathrm{m}$.

sive water is supplied to greenhouse tomatoes grown in bags, fruit cracking increases as the tomato plant receives more water (Peet and Willits, 1995). In hydroponics, fruit cracking has been observed in both open and closed systems (Maboko et al., 2011). The anatomical characteristics of cultivars susceptible to fruit cracking are: 1) large fruit size, 2) low skin tensile strength and/or low skin extensibility when turning to the pink stage of maturity, 3) thin skin, 4) thin pericarp, 5) shallow cutin penetration, 6) fewer fruits per plant, 7) fruit not covered by foliage (Peet, 1992). It has been reported that UV-A irradiation increases the firmness of fruit (Mariz-Ponte et al., 2019) and that it does not damage the epidermis (Maneerat et al., 2003). In our study, too, because a DFT system similar to a hydroponic cultivation system was adopted, no difference in fruit cracking rate was observed in the sections and no anatomical or histochemical differences were observed between the cultivation areas in terms of epidermal structure; therefore, it was considered that fruit cracking occurred due to the cultivation environment in which the tomato plants received more water.

Maboko and Du Plooy (2013a, b) reported that when several tomato cultivars were grown at different plant densities, less fruit cracking was observed at higher plant densities than at lower ones. This paper suggested that a high planting density resulted from high canopy coverage and reduced the exposure of fruits to direct sunlight and high temperatures. Therefore, this study could not clarify whether planting density affected the occurrence of fruit splitting, which is an important issue as well as the irrigation status of the plant body in plant factories. Matsuo et al. (2012) suggested that cytokinins 
(CK) are involved in cell division during tomato fruit development by applying a synthetic CK, forchlorfenuron (1-(2-chloro-4-pyridyl)-3-phenylurea, CPPU), to unpollinated tomato ovaries to induce parthenocarpic fruit development. A single spraying of CPPU on tomato fruit clusters (fruit size: $3.0-4.9 \mathrm{~cm}$ diameter) reduced fruit cracking as a result of an increase in the number of cells near the epidermis (Sano et al., 2018). In addition, the effectiveness of UV-cut film (UV protection film) has been reported to reduce tomato fruit cracking in open field cultivation (Kimura et al., 2012; Uetani et al., 2014; Suzuki, 2019). It is possible to use this method based on the intensity and duration of UV irradiation. Therefore, it could be incorporated into tomato cultivation in plant factories that control the environment, and we plan to further investigate the appropriate conditions needed to suppress tomato fruit cracking.

\section{Effects of ultraviolet radiation on fruit components}

The TSS of ripe tomato fruit was significantly higher in t-UVA than non-UVA at $P<0.001$ by two-way ANOVA, but there was no significant difference by cultivar (Table 2). A difference with the UV-A irradiation treatment was observed and a significant difference was observed in the interaction between cultivar and section $(\mathrm{C} \times \mathrm{S})$ at $P<0.05$. The t-UVA in 'Tiny Tim Red' had the highest TSS compared to the other fruits by Tukey's test at $P<0.05$ (Table 2). A difference in the TA was observed in the cultivars, sections and $(\mathrm{C} \times \mathrm{S})$ this was significant at $P<0.001$ (Table 2). The non-UVA of 'Tiny Tim Red' was significantly higher than other TAs by Tukey's test at $P<0.05$. The TSS to TA ratio was FL: 19.9, UV-A: 16.2 in 'Red Robin' and FL: 8.8, UVA: 10.6. Previous studies reported that harvested tomato fruit with irradiated UV-B for $8 \mathrm{~min}\left(2.35 \mathrm{~W} \cdot \mathrm{m}^{-2}\right)$ increased the TSS content (Kasim and Kasim, 2015). On the other hand, Mariz-Ponte et al. (2019) reported that tomato plants with irradiated UV-A $\left(0.8 \mathrm{~W} \cdot \mathrm{m}^{-2}\right)$ for $1 \mathrm{~h}$ and $4 \mathrm{~h}$ or UV-B $\left(2.9 \mathrm{~W} \cdot \mathrm{m}^{-2}\right)$ for $2 \mathrm{~min}$ and $5 \mathrm{~min}$ had reduced TSS content. In our study, it was shown that the TSS content increased under the influence of UV irradiation, as in Kasim and Kasim (2015), even though the harvested fruits were not UV-irradiated. Cote et al. (2013) reported that irradiation of postharvest fruits with UV-C radiation for 2 min (peak emission: $254 \mathrm{~nm} ; 33 \mathrm{~W} \cdot \mathrm{m}^{-2}$ ) slightly reduced the TA and Dyshlyuk et al. (2020) reported that the TA was hardly affected by UV-A radiation (UV intensity: $353 \mathrm{~nm}, 365 \mathrm{~nm}$ and $400 \mathrm{~nm}$; UV irradiated continuously for $10 \mathrm{~min}, 180 \mathrm{~min}$, and $360 \mathrm{~min}$ at the following doses: $0.33,0.28$ and $0.28 \mathrm{~W} \cdot \mathrm{m}^{-2}$, respectively for UV intensity types). It was considered that the increase in the TA was related to the irradiation time of UV-A and the irradiation intensity because it was different from the results of this study, in which the TA increased when irradiated with UV-A.

The ascorbic acid content of 'Tiny Tim Red' was significantly higher than that of 'Red Robin' at $P<0.001$, and the UV-A irradiation treatment showed a significant effect on the ascorbic acid content in the fruit at $P<$ 0.001 (Table 2). There was a significant difference in the $(\mathrm{C} \times \mathrm{S})$ at $P<0.05$ and, the t-UVA of 'Tiny Tim Red' had significantly the highest ascorbic acid content compared to the other fruits by Tukey's test at $P<0.05$ (Table 2). Previous papers reported an increase in the ascorbic acid with UV-B $\left(1.69 \mathrm{~W} \cdot \mathrm{m}^{-2}\right)$ or UV-C irradiation of post-harvest fruits (Jagadeesh et al., 2011; Castagna et al., 2013), and it is considered that the ascorbic acid also increased due to the effect of the UVA irradiation in this study.

The lycopene content of 'Tiny Tim Red' and nonUVA was significantly higher than that of 'Red Robin' at $P<0.001$, and the UV-A irradiation treatment reduced the lycopene content of the fruit at $P<0.05$ (Table 2). There was no significant difference in the $(\mathrm{C} \times \mathrm{S})$ by two-way ANOVA. The $\beta$-carotene content was significantly different in the cultivars and sections at $P<0.001$ and at $P<0.05$, respectively. There was a significant difference in the interaction at $P<0.001$, and the non-UVA of 'Tiny Tim Red' had the highest $\beta$-carotene and lycopene content of all sections by

Table 2. Effects of UV radiation on fruit components of 'Red Robin' and 'Tiny Tim Red'.

\begin{tabular}{|c|c|c|c|c|c|c|}
\hline Cultivar & Section & $\begin{array}{l}\text { Total soluble solids } \\
\text { (Brix }(\%))\end{array}$ & $\begin{array}{l}\text { Titratable acidity } \\
(\mathrm{g} / \mathrm{L})\end{array}$ & $\begin{array}{c}\text { Ascorbic acid } \\
(\mathrm{mg} / \mathrm{L})\end{array}$ & $\begin{array}{c}\text { Lycopene } \\
(\mathrm{mg} / \mathrm{L})\end{array}$ & $\begin{array}{c}\beta \text {-carotene } \\
(\mathrm{mg} / \mathrm{L})\end{array}$ \\
\hline \multirow{2}{*}{ 'Red Robin' } & non-UVA & $5.3 \pm 0.1^{y} b^{x}$ & $2.66 \pm 0.02 \mathrm{~d}$ & $181.6 \pm 2.2 \mathrm{~d}$ & $57.0 \pm 3.1$ & $19.8 \pm 0.8 \mathrm{c}$ \\
\hline & $\mathrm{t}$-UVA & $5.4 \pm 0.1 \mathrm{ab}$ & $3.36 \pm 0.03 \mathrm{c}$ & $240.4 \pm 3.5 \mathrm{c}$ & $55.3 \pm 0.6$ & $21.3 \pm 0.7 b c$ \\
\hline \multirow{2}{*}{ 'Tiny Tim Red' } & non-UVA & $5.2 \pm 0.1 \mathrm{~b}$ & $5.90 \pm 0.03 \mathrm{a}$ & $254.4 \pm 1.8 \mathrm{~b}$ & $76.3 \pm 1.3$ & $33.0 \pm 1.2 \mathrm{a}$ \\
\hline & $\mathrm{t}$-UVA & $5.7 \pm 0.1 \mathrm{a}$ & $5.42 \pm 0.03 \mathrm{~b}$ & $301.2 \pm 2.2 \mathrm{a}$ & $69.2 \pm 1.6$ & $24.4 \pm 1.5 \mathrm{~b}$ \\
\hline \multirow{3}{*}{ Significance $^{\mathrm{z}}$} & Cultivar (C) & NS & $* * *$ & $* * *$ & $* * *$ & $* * *$ \\
\hline & Section (S) & $* * *$ & $* * *$ & $* * *$ & $*$ & $*$ \\
\hline & $(\mathrm{C}) \times(\mathrm{S})$ & * & $* * *$ & * & NS & $* * *$ \\
\hline
\end{tabular}

\footnotetext{
${ }^{z}$ NS indicate not significant; asterisks are significant differences at *** $P<0.001, * * P<0.01, * P<0.05$ by two-way ANOVA.

y The data are mean \pm standard error $(n=5)$.

${ }^{x}$ Different letters within a category of column are significant differences by Tukey's test at $P<0.05$.
} 
Tukey's test at $P<0.05$ (Table 2). Giuntini et al. (2005) showed that tomato plants grown in a greenhouse with UV-B had a higher $\beta$-carotene and lycopene content than tomato plants grown without UV-B. Castagna et al. $(2013,2014)$ and Dyshlyuk et al. (2020) also reported that post-harvest UV-B or UV-A radiation increased the content of $\beta$-carotene and lycopene. In these reports, UV-B radiation of tomato plants or fruits promoted further carotenoid accumulation. In our study, the carotenoid content showed a decrease, except for $\beta$-carotene in the UV-A of 'Red Robin', which was different from these reports. In Perez et al. (2009), UV-B irradiation $\left(0.075 \mathrm{Wh} \cdot \mathrm{m}^{-2}, 22 \mathrm{~h}\right)$ of pre-harvest tomatoes 'Liberto' showed a maximum increase in $\beta$-carotene and lycopene content, but a reduction in carotenoid content was observed depending on the ultraviolet irradiation intensity and irradiation time. Therefore, in this study, too, it was considered that the $\beta$-carotene and lycopene content decreased due to UVA irradiation at a higher irradiation intensity than in other reports during the cultivation period until the harvest date.

In conclusion, we examined the cultivation of the dwarf cherry tomatoes 'Red Robin' and 'Tiny Tim Red' for use in a plant factory with artificial light and investigated the effect of ultraviolet radiation. Our research showed that UV irradiation had a positive effect on the TSS, TA and ascorbic acid, and a negative effect on fruit size per fruit and carotenoid content. UV irradiation did not affect the yield per plant. Comparing 'Red Robin' and 'Tiny Tim Red', there was no significant difference in yield, but the fruit size of 'Red Robin' was larger than the other fruits, and the fruit component of 'Tiny Tim Red' was higher than that of 'Red Robin'. Therefore, when cultivating tomato plants in a plant factory, further improvements in fruit size and fruit composition are expected by appropriately adjusting the time and intensity of UV irradiation for each cultivar.

\section{Acknowledgements}

We wish to thank Tamagawa University Research Institute Biosystems \& Biofunctions Research Center for the use of the plant factory with artificial light and the researchers at the center for supplying kind advice. We thank students and all our colleagues for their assistance in the research for this paper.

\section{Literature Cited}

Bacci, L., D. Grifoni, F. Sabatini and G. Zipoli. 1999. UV-B radiation causes early ripening and reduction in size of fruits in two lines of tomato (Lycopersicon esculentum Mill.). Glob. Change Biol. 5: 635-646.

Benke, K. and B. Tomkins. 2017. Future food-production systems: vertical farming and controlled-environment agriculture. Sustain. Sci. Pract. Policy 13: 13-26.

Castagna, A., E. Chiavaro, C. Dall'Asta, M. Rinaldi, G. Galaverna and A. Ranieri. 2013. Effect of postharvest UV-B irradiation on nutraceutical quality and physical properties of tomato fruits. Food Chem. 137: 151-158.

Castagna, A., C. Dall'Asta, E. Chiavaro, G. Galaverna and A. Ranieri. 2014. Effect of post-harvest UV-B irradiation on polyphenol profile and antioxidant activity in flesh and peel of tomato fruits. Food Bioprocess Technol. 7: 2241-2250.

Cote, S., L. Rodoni, E. Miceli, A. Concellón, P. M. Civello and A. R. Vicente. 2013. Effect of radiation intensity on the outcome of postharvest UV-C treatments. Postharvest Biol. Technol. 83: 83-89.

Dyshlyuk, L., O. Babich, A. Prosekov, S. Ivanova, V. Pavsky and T. Chaplygina. 2020. The effect of postharvest ultraviolet irradiation on the content of antioxidant compounds and the activity of antioxidant enzymes in tomato. Heliyon 6: e03288. DOI: 10.1016/j.heliyon.2020.e03288.

Giuntini, D., G. Graziani, B. Lercari, V. Fogliano, G. F. Soldatini and A. Ranieri. 2005. Changes in carotenoid and ascorbic acid contents in fruits of different tomato genotypes related to the depletion of UV-B radiation. J. Agric. Food Chem. 53: 3174-3181.

He, R., Y. Zhang, S. Song, W. Su, Y. Hao and H. Liu. 2020. UV$\mathrm{A}$ and FR Irradiation improves growth and nutritional properties of lettuce grown in an artificial light plant factory. Food Chem. 345: 128727.

Jagadeesh, S. L., M. T. Charles, Y. Gariepy, B. Goyette, G. S. V. Raghavan and C. Vigneault. 2011. Influence of postharvest UV-C hormesis on the bioactive components of tomato during posttreatment handling. Food Bioprocess Technol. 4: 1463-1472.

Jensen, W. A. 1962. Botanical histochemistry: principles and practice. W. H. Freeman and Company, California.

Kanda, Y. 2013. Investigation of the freely available easy-touse software 'EZR' for medical statistics. Bone Marrow Transplant. 48: 452-458.

Kasim, M. U. and R. Kasim. 2015. Postharvest UV-B treatments increased fructose content of tomato (Solanum lycopersicon L. cv. Tayfun F1) harvested at different ripening stages. Food Sci. and Technol. Campinas 35: 742-749.

Kato, K., S. Maruyama, T. Hirai, K. Hiwasa-Tanase, T. Mizoguchi, E. Goto and H. Ezura. 2011. A trial of production of the plant-derived high-value protein in a plant factory: photosynthetic photon fluxes affect the accumulation of recombinant miraculin in transgenic tomato fruits. Plant Signal. Behav. 6: 1172-1179.

Kato, K., R. Yoshida, A. Kikuzaki, T. Hirai, H. Kuroda, K. Hiwasa-Tanase, K. Takane, H. Ezura and T. Mizoguchi. 2010. Molecular breeding of tomato lines for mass production of miraculin in a plant factory. J. Agric. Food Chem. 58: 9505-9510.

Kimura, M., S. Fujitani and K. Itimanda. 2012. Mitigation techniques on fruit cracking in tomato cultivation under rain shelter in summer and autumn. Bull. Oita Agric. Forest. Fish. Res. Cent. 2: 23-42 (In Japanese).

Kozai, T. 2013a. Plant factory in Japan-Current situation and perspectives. Chron. Hortic. 53: 8-11.

Kozai, T. 2013b. Resource use efficiency of closed plant production system with artificial light: Concept, estimation and application to plant factory. Proc. Jan. Acad. Ser. B 89: 447461.

Lee, M. J., J. E. Son and M. M. Oh. 2014. Growth and phenolic compounds of Lactuca sativa L. grown in a closed-type plant production system with UV-A, -B, or -C lamp. J. Sci. Food Agric. 94: 197-204.

Maboko, M. M. and C. P. Du Plooy. 2013a. Alternative method of optimizing yield of tomatoes in a closed hydroponic system. Acta Hortc. 1007: 579-585. 
Maboko, M. M. and C. P. Du Plooy. 2013b. High-density planting of tomato cultivar's with early decapitation of growing point increased yield in a closed hydroponic system. Acta Agric. Scand. Sect. B Soil Plant Sci. 63: 676-682.

Maboko, M. M., C. P. Du Plooy and I. Bertling. 2011. Comparative performance of tomato cultivars cultivated in two hydroponic production systems. S. Afr. J. Plant Soil 28: 97 102.

Maneerat, C., Y. Hayata, N. Muto and M. Kuroyanagi. 2003. Investigation of UV-A light irradiation on tomato fruit injury during storage. J. Food Protect. 66: 2168-2170.

Mariz-Ponte, N., S. Martins, A. Gonçalves, C. M. Correia, C. Ribeiro, M. C. Dias and C. Santos. 2019. The potential use of the UV-A and UV-B to improve tomato quality and preference for consumers. Sci. Hortic. 246: 777-784.

Matsuo, S., K. Kikuchi, M. Fukuda, I. Honda and S. Imanishi. 2012. Roles and regulation of cytokinins in tomato fruit development. J. Exp. Bot. 63: 5569-5579.

Nagata, M. and I. Yamashita. 1992. Simple method for simultaneous determination of chlorophyll and carotenoids in tomato fruit. Nippon Shokuhin Kogyo Gakkaishi 39: 925-928 (In Japanese with English abstract).

Ohashi-Kaneko, K., W. Imai, T. Tabuchi, T. Kobayashi and H. Watanabe. 2017. Yield and fruit quality of several wild and domestic tomato cultivars grown in an environmentally controlled agricultural facility (plant factory). Acta Hortic. 1170: 989-994.

Peet, M. M. 1992. Fruit cracking in tomato. HortTechnology 2:
210-223.

Peet, M. M. and D. H. Willits. 1995. Role of excess water in tomato fruit cracking. HortScience 30: 65-68.

Perez, C. P., C. Ulrichs, S. Huyskens-Keil, M. Schreiner, A. Krumbein, D. Schwarz and H. P. Kläring. 2009. Composition of carotenoids in tomato fruits as affected by moderate UV-B radiation before harvest. Acta Hortic. 821: 217-222.

Sano, O., M. Hikawa and S. Imanishi. 2018. Reduction of radial fruit cracking by single spraying of forchlorfenuron (1-(2chloro-4-pyridyl)-3-phenylurea) of fruit clusters in tomato production under rain shelter. Hort. Res. (Japan) 17: 87-93 (In Japanese with English abstract).

Shamshiri, R. R., F. Kalantari, K. C. Ting, K. R. Thorp, I. A. Hameed, C. Weltzien, D. Ahmad and Z. M. Shad. 2018. Advances in greenhouse automation and controlled environment agriculture: A transition to plant factories and urban agriculture. Int. J. Agric. Biol. Eng. 11: 1-22.

Suzuki, K. 2019. Physiological disorders and their management in greenhouse tomato cultivation at high temperatures. p. 81-96. In: T. Iizumi, R. Hirata and R. Matsuda (eds.). Adaptation to climate change in agriculture. Springer, Singapore.

Uetani, M., S. Fujitani and M. Kimura. 2014. Mitigation techniques on fruit cracking in tomato cultivation under rain shelter in summer and autumn II. Bull. Oita Agric. Forest. Fish. Res. Cent. 4: 11-25 (In Japanese with English abstract). 